13

\title{
Слои кремния, гиперпересыщенные теллуром, для фотодиодов видимого и инфракрасного диапазонов
}

\author{
(C) Ф.Ф. Комаров, ${ }^{1,2}$ С.Б. Ластовский, ${ }^{3}$ И.А. Романов, ${ }^{4}$ И.Н. Пархоменко, ${ }^{4}$ Л.А. Власукова, ${ }^{4}$ Г.Д. Ивлев, ${ }^{4}$ \\ Y. Berencen, ${ }^{5}$ А.А. Цивако, ${ }^{6}$ Н.C. Ковальчук, ${ }^{6}$ E. Wendler ${ }^{7}$
}

${ }^{1}$ Научно-исследовательское учреждение Институт прикладных фризических проблем им. А.Н. Севченко Белорусского государственного университета,

220045 Минск, Беларусь

${ }^{2}$ Научно-исследовательский технологический университет „МИСиС“,

119049 Москва, Россия

${ }^{3}$ Научно-практический центр НАН Беларуси по материаловедению,

220072 Минск, Беларусь

${ }^{4}$ Белорусский государственный университет,

220030 Минск, Беларусь

${ }^{5}$ Центр им. Гельмгольца Дрезден-Россендорф, Институт ионно-лучевой фризики и материаловедения,

01328 Дрезден, Германия

'ОАО „Интеграл“,

220108 Минск, Беларусь

${ }^{7}$ Йенский университет им. Ф. Шиллера,

07743 Йена, Германия

e-mail: komarovf@bsu.by

Поступило в Редакцию 13 мая 2021 г.

В окончательной редакции 3 августа 2021 г.

Принято к публикации 5 августа 2021 г.

Методом ионной имплантации с последующим импульсным лазерным отжигом сформированы слои кремния, легированные теллуром, до концентраций $(3-5) \cdot 10^{20} \mathrm{~cm}^{-3}$. Показано, что $70-90 \%$ внедренной примеси находится в позиции замещения в решетке кремния. Слои $\mathrm{Si}$, гиперпересыщенные теллуром, обеспечивают существенное поглощение как в видимом диапазоне, так и в области длин волн $1100-2500 \mathrm{~nm}$ (35-65\%), причем коэффициент поглощения увеличивается с ростом длины волны. Приведены и обсуждаются вольт-амперные и вольт-фарадные характеристики, а также фоточувствительность фотодетекторов на слоях кремния, легированного теллуром. Рассмотрена специфика остаточных дефектов структуры в легированных слоях $\mathrm{Si}$ на основе данных нестационарной спектроскопии глубоких уровней.

Ключевые слова: кремний, гипердопирование, имплантация теллура, лазерный отжиг, примесная подзона, нестационарная спектроскопия глубоких уровней.

DOI: $10.21883 /$ JTF.2021.12.51769.144-21

\section{Введение}

Кремний является основным полупроводниковым материалом, используемым для производства интегральных микросхем, и занимает доминирующее положение на рынке с долей около 90\%. Кремниевые чипы с ультравысоким уровнем интеграции образуют основу современной микроэлектроники и обеспечивают экспоненциальный рост производительности вычислительной техники. Быстродействие интегральных схем (микропроцессоров, графических чипов, микросхем оперативной памяти и т.п.) определяется скоростью переключения составляющих МОП-транзисторов и скоростью обмена данными. За последние три десятилетия быстродействие активных элементов, размещенных на кремниевом кристалле, удваивалось каждые полтора-два года (закон Мура), в то время как скорость носителей в металлических проводниках, соединяющих отдельные компоненты интегральной схемы, оставалась неизменной. Если производительность первых процессоров определялась главным образом быстродействием транзисторов, то в настоящий момент вклад межсоединений в общее время задержки на логических элементах сопоставим или даже превышает время переключения транзисторов. Таким образом, именно время соединения и обмена информацией между составляющими элементами определяет предел быстродействия „традиционных“ микропроцессоров. Наиболее многообещающим решением проблемы увеличения быстродействия будущих интегральных схем является оптическая передача данных внутри Siкристалла. Оптические межсоединения обеспечивают скорость передачи данных 30-60 Gbps, предел медной технологии оценивается в $20 \mathrm{Gbps}[1,2]$. К тому же оптоэлектронные устройства потребляют значительно меньшую мощность. В последние годы специалисты в области микро- и оптоэлектроники усиленно работают над созданием высокоэффективных излучателей и приемников излучения в видимой (от $\sim 0.3$ до $\sim 0.8 \mu \mathrm{m})$, 
ближней инфракрасной (ИК) (от $\sim 0.8$ до $\sim 2 \mu \mathrm{m})$ и средней ИК (от $\sim 2$ до $\sim 25 \mu \mathrm{m})$ областях, волноводов и модуляторов на кремнии, изготовление которых позволит объединить электронные и оптические приборы в единой интегральной схеме [1-4]. В интегрированных приборах кремниевой фотоники детекторы должны регистрировать фотоны с энергией меньше, чем ширина запрещенной зоны $\mathrm{Si}\left(E_{g}=1.12 \mathrm{eV}\right.$ или с длиной волны более $1.1 \mu \mathrm{m}$ ), которые могут эффективно распространяться с минимумом потерь внутри оптоволокна или иных волноводных сред. Существующие кремниевые фотодетекторы нечувствительны к трем основным полосам оптоволоконных телекоммуникационных систем: $\mathrm{S}(1460-1530), \mathrm{C}(1530-1565)$ и L (1565-1625) nm [5].

В течение последних лет разрабатывались и апробировались различные стратегии создания фотодетекторов ближнего и среднего ИК диапазонов на кремнии с эффективной фоточувствительностью. К ним следует отнести разработку фотодетекторов на основе гетероструктур 4-ой группы сплавов $\mathrm{Si}-\mathrm{Ge}$ [4] и создание фоточувствительных слоев за счет модификации зонной структуры и генерации промежуточных состояний в запрещенной зоне $\mathrm{Si}$ за счет облучения ионами $\mathrm{Si}^{+}$, $\mathrm{Ar}^{+}$, протонами или нейтронами [6,7]. В первом из упомянутых подходов из-за несоответствия параметров решеток в $4.2 \%$ между слоями $\mathrm{Si}$ и $\mathrm{Ge}$ формируемые эпитаксиальные слои $\mathrm{Ge}$ обладали высокой плотностью проникающих дислокаций и высокой шероховатостью поверхности, что препятствует интеграции таких слоев $\mathrm{Ge}$ в КМОП кремниевой планарной технологии. В рамках второго подхода сформированные за счет радиационных воздействий слои кремния способны генерировать носители тока за счет квантов с $\hbar \omega<E_{g}^{\mathrm{Si}}$, однако коэффициент поглощения таких слоев оказался весьма невысоким $\left(\alpha \approx 0.5-50 \mathrm{~cm}^{-1}\right)$ [6].

Альтернативным вариантом является введение состояний в запрещенную зону путем легирования Si традиционными примесями $p$ - и $n$-типа, т. е. групп III (B, $\mathrm{Al}$ и $\mathrm{Ga})$ и $\mathrm{V}(\mathrm{P}, \mathrm{As}$ и $\mathrm{Sb})$, что обеспечивает поглощение квантов ИК диапазона $[8,9]$. Si-фотодетекторы на основе мелких легирующих примесей проявляют широкополосную фоточувствительность, но работают при температурах ниже $40 \mathrm{~K}$ из-за интенсивной термической генерации свободных носителей при более высоких температу$\operatorname{pax}[10]$. В результате термоионизация носителей влияет на соотношение выхода оптической генерации к их термогенерации, что препятствует применению таких фотоприемников при комнатной температуре.

Ряд ведущих лабораторий мира микро- и оптоэлектронного профиля провели разработку и исследование фотоприемников за счет реализации принципов создания примесных подзон в запрещенной зоне $\mathrm{Si}$ путем введения примесей, создающих глубокие уровни с энергией ионизации сотни $\mathrm{meV}[11,12]$. Такие фотоприемники ближнего и среднего ИК диапазонов способны эффективно работать при комнатных температурах. Следует отметить, что предел равновесной растворимости примесей, создающих глубокие уровни в кремнии, составляет $\sim 10^{16} \mathrm{~cm}^{-3}$ [13], что на несколько порядков ниже, чем эта величина для мелких легирующих примесей (свыше $10^{19} \mathrm{~cm}^{-3}$ ) [13]. Важно то, что для формирования примесной подзоны в запрещенной зоне кремния концентрация легирующей примеси должна превышать $10^{18} \mathrm{~cm}^{-3}$ [14]. Это свидетельствует о том, что для создания таких высоких уровней легирования требуются неравновесные методы термообработок. Следует отметить, что имеется еще одно препятствие в реализации высоких концентраций таких примесей: их высокая диффузионная подвижность в $\mathrm{Si}$. В отличие от мелких легирующих примесей коэффициенты диффузии примесей, создающих глубокие уровни, оказываются на многие порядки величины выше [15]. Это говорит о том, что длинные по времени процессы термообработок неприемлемы.

К настоящему времени установлено, что наибольший коэффициент поглощения света в ИК диапазоне (до $\sim 3 \mu \mathrm{m})$ при комнатной температуре $\left(\sim 10^{4} \mathrm{~cm}^{-1}\right)$ наблюдается у монокристаллического кремния, пересыщенного атомами халькогенов (S, Se, Te) [16].

Равновесная растворимость халькогенов в кремнии также составляет $\sim 10^{16} \mathrm{~cm}^{-3}$. При таких концентрациях халькогены создают глубокие уровни в запрещенной зоне кремния. Однако при превышении равновесной растворимости на 4-5 порядков примесные уровни сливаются в подзону. Становится возможным поглощение фотонов через электронные переходы „валентная зона-примесная подзона“ и „примесная подзона-зона проводимости““ [17]. Чтобы добиться гиперпересыщения, легирование кремния халькогенами проводят с использованием неравновесных методов, таких, как ионная имплантация с последующим фемто-, пико-, наносекундным лазерным $[16,18,19]$ или флэш отжигом [20].

Настоящая работа посвящена созданию гиперпересыщенных теллуром слоев $\mathrm{Si}$ с использованием ионной имплантации и импульсного лазерного отжига. Исследования сфокусированы на определении влияния режимов импульсного лазерного отжига (ИЛО, PLA) на структурные, оптические и электрофизические свойства легированных слоев. Изготовлены тестовые структуры фотодиодов и измерены их вольт-амперные и вольтфарадные характеристики. Приведена оценка фоточувствительности структур, сформированных при различных режимах ИЛО, к излучениям видимого и ближнего ИК диапазонов, а также влияние последующей низкотемпературной обработки $\left(400^{\circ} \mathrm{C}\right)$ на вольт-амперные характеристики (BAX).

\section{1. Материалы и методы исследования}

Пластины $\mathrm{Si}(111)$ p-типа проводимости с удельным сопротивлением $\rho=10 \Omega \cdot \mathrm{cm}$, полированные с двух сторон, были имплантированы ионами $\mathrm{Te}^{+}$с энергией 
$200 \mathrm{keV}$ дозой $1 \cdot 10^{16} \mathrm{~cm}^{-2}$. Затем проводился импульсный лазерный отжиг рубиновым лазером $(\lambda=694 \mathrm{~nm}$, длительность отжига $\sim 70 \mathrm{~ns}$ по уровню 0.5 при однородном распределении энергии импульса по зоне ИЛО размером $4 \times 4 \mathrm{~mm})$. Плотность энергии $W$ в лазерном импульсе (зоне ИЛО) задавалась равной $1.5,2$ и $2.5 \mathrm{~J} / \mathrm{cm}^{2}$. В ряде случаев использовался дополнительный низкотемпературный отжиг образцов $\left(400^{\circ} \mathrm{C}, 15 \mathrm{~min}\right)$ в потоке аргона $(200 \mathrm{sccm})$.

Анализ распределения внедренной примеси по глубине, доли атомов теллура в узлах решетки кремния и степени кристалличности имплантированных слоев проводился методом регистрации спектров резерфордовского обратного рассеяния $(\mathrm{POP})$ ионов $\mathrm{He}^{+}$с энергией $1.5 \mathrm{MeV}$ в режиме каналирования (POP/K, RBS/Ch) вдоль направления „100“ и без него. Моделирование спектров POP с помощью программы SIMNRA [21] выполнялось ступенчато до полного совпадения с экспериментальными спектрами. Для исследования оптических свойств снимались спектры комбинационного рассеяния света (КРС), пропускания $(T)$ и отражения $(R)$. Спектры КРС регистрировались в геометрии обратного рассеяния на микрорамановском спектрометре Ramanor U1000 (Jobin Yvon) при возбуждении лазером с длиной волны $532 \mathrm{~nm}$. Спектры пропускания и отражения снимались на спектрофотометре Lambda 1050 WB (PerkinElmer) в диапазоне $200-2500 \mathrm{~nm}$. Спектр поглощения $(A)$ рассчитывался по формуле

$$
A=100 \%-R-T \text {. }
$$

Измерение ВАХ проводилось с использованием измерителя параметров полупроводниковых приборов ИППП1/6 при температуре измерения $T_{r e g}=290$ и $80 \mathrm{~K}$. Характеристики измерялись с подсветкой и без подсветки (темновые). Распределение концентрации носителей заряда $N(x)$ в менее легированной области исследуемых структур определялось из анализа вольтфарадных $(C-U)$ зависимостей. Данный метод основан на регистрации значений емкости резко ассиметричного $p-n$-перехода при изменении величины обратного напряжения смещения $U_{r e v}$. Барьерная емкость $n^{+}-p$ структур измерялась при $T_{r e g}=290$ и $80 \mathrm{~K}$ на частоте $1 \mathrm{MHz}$ с помощью измерителя LCR E7-17.

Определение характеристик остаточных дефектов структуры (энергия активации эмиссии и сечение захвата носителей заряда) осуществлялось методом нестационарной емкостной спектроскопии глубоких уровней (Deep Level Transient Spectroscopy - DLTS) [22]. Измерение проводилось на емкостном спектрометре на базе высокочастотного моста полной проводимости с автоматической балансировкой по емкости. Кроме того, в состав установки входили: система регистрации и управления автоматикой на основе персонального компьютера, блок регулировки температуры и азотный криостат.

\section{2. Результаты и их обсуждение}

\section{1. Структура и элементный состав}

На рис. 1 представлены спектры РОР/К. Как видно из рисунка, ИЛО вызывает диффузионное перераспределение примеси как вглубь образца, так и к поверхности.

На рис. 2 представлены концентрационные профили распределения примеси, полученные путем моделирования в программе SIMNRA до полного совпадения экспериментальных и моделированных спектров. По-

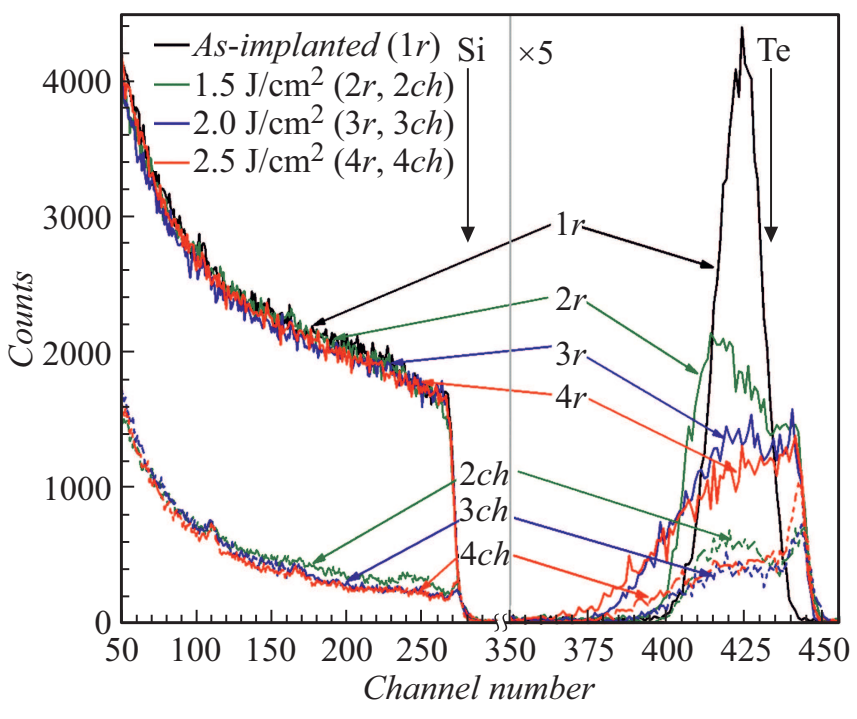

Рис. 1. Спектры РОР/К образцов $\mathrm{Si}$, гиперпересыщенного Те: 1 - исходный, $2-4-$ после отжига: $2-1.5,3-2$, $4-2.5 \mathrm{~J} / \mathrm{cm}^{2}$. Спектры $1 r-4 r$ сняты в режиме „random“, спектры $2 c h-4 c h$ сняты в режиме каналирования.

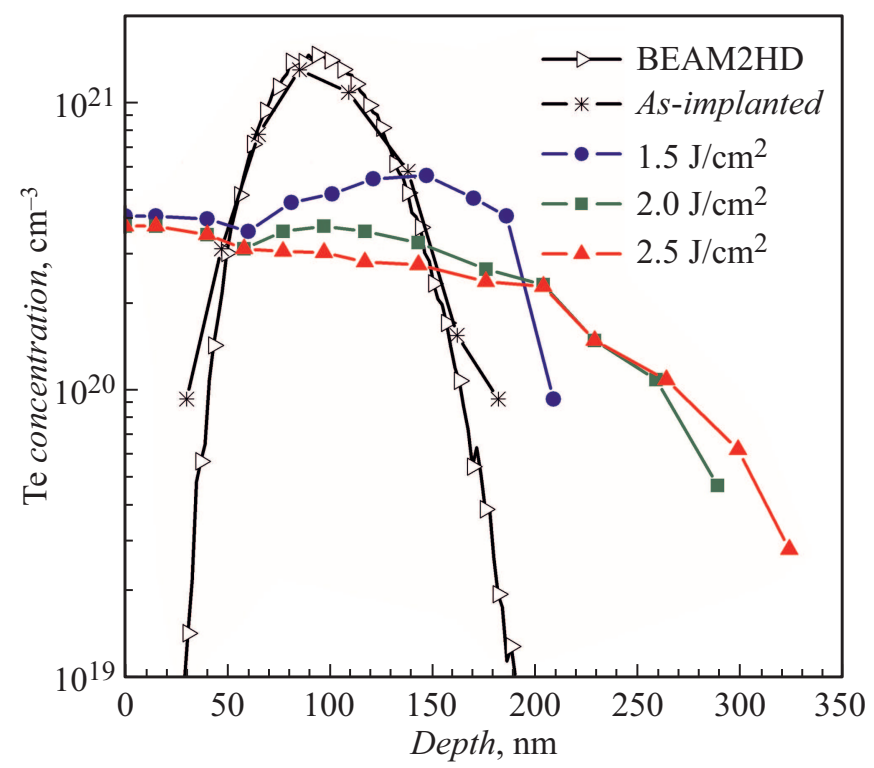

Рис. 2. Смоделированный профиль концентрации атомов теллура и экспериментальные концентрационные профили атомов теллура для имплантированного образца $\mathrm{Si}$ без отжига и для различных режимов термообработки. 
казан также концентрационный профиль внедренной примеси, рассчитанный с использованием программы BEAM2HD [23]. Следует отметить хорошее количественное соответствие данных теории и эксперимента как по положению максимума концентрации, так и по величине концентрации как функции глубины во всем диапазоне концентраций, регистрируемых РОР. Сразу после имплантации концентрация теллура в максимуме на глубине $\sim 80 \mathrm{~nm}$ составляет $\sim 1 \cdot 10^{21} \mathrm{~cm}^{-3}$. После лазерной обработки при $W=1.5 \mathrm{~J} / \mathrm{cm}^{2}$ в области глубин от поверхности до $190 \mathrm{~nm}$ формируется концентрационное плато, в области которого концентрация теллура достигает $(4-5) \cdot 10^{20} \mathrm{~cm}^{-3}$. При плотностях энергии лазерного импульса 2.0 и $2.5 \mathrm{~J} / \mathrm{cm}^{2}$ концентрация теллура в области плато снижается до $3 \cdot 10^{20} \mathrm{~cm}^{-3}$ за счет диффузии части примеси вглубь образца до глубин 300 и $330 \mathrm{~nm}$ после ИЛО с $W=2.0$ и $2.5 \mathrm{~J} / \mathrm{cm}^{2}$ соответственно. Интегральное количество атомов внедренной примеси, определенное из распределений концентраций атомов по глубине кремния, приведенных на рис. 2, составляет $1 \cdot 10^{16} \mathrm{~cm}^{-2}$ для имплантированного образца без отжига и для образца после ИЛО с плотностью энергии $W=1.5 \mathrm{~J} / \mathrm{cm}^{2}, 0.9 \cdot 10^{16} \mathrm{~cm}^{-2}$ и $0.8 \cdot 10^{16} \mathrm{~cm}^{-2}$ для отжига с $W=2.0 \mathrm{~J} / \mathrm{cm}^{2}$ и $W=2.5 \mathrm{~J} / \mathrm{cm}^{2}$ соответственно. Учитывая точности измерения флюенса ионов при имплантации и анализе концентрационных профилей (чувствительность метода РОР $\sim 0.01$ at.\%), можно отметить слабое влияние режима ИЛО на общее содержание примеси с тенденцией к ее уменьшению с увеличением плотности энергии лазерного импульса.

Спектры РОР, снятые в режиме каналирования, свидетельствуют о том, что имплантированный теллуром слой $\mathrm{Si}$ без ИЛО находится в аморфном состоянии. Толщина аморфного слоя $\mathrm{Si}$ после имплантации ионов $\mathrm{Te}^{+}$с флюенсом $1 \cdot 10^{16} \mathrm{~cm}^{-2}$ без ИЛО, полученная из спектра РОР/К для этого образца (не приводим), составляет $\sim 0.2 \mu \mathrm{m}$. Для оценки степени кристалличности $\mathrm{Si}$ и доли Те в позициях замещения в решетке $\mathrm{Si}$ использованы величины $\chi^{\mathrm{Si}}$ и $\chi^{\mathrm{Te}}$, которые показывают интегральные отношения отсчетов каналированного к неориентированному спектру в каналах, связанных с $\mathrm{Si}$ и Те соответственно. Доля атомов примеси в узлах решетки кремния $f$ рассчитывалась по формуле из работы [24]:

$$
f=\left(1-\chi^{\mathrm{Te}}\right) /\left(1-\chi^{\mathrm{Si}}\right)
$$

Значения $\chi^{\mathrm{Si}}$ и $f$ представлены в табл. 1 .

Как видно из табл. 1 , диапазон значений $\chi^{\mathrm{Si}}$ кремния, гиперпересыщенного теллуром, после ИЛО составляет $23.9-21.2 \%$, причем с ростом плотности энергии в импульсе $\chi^{\mathrm{Si}}$ снижается. Для сравнения в идеальном монокристалле $\chi^{\mathrm{Si}} \leq 5 \%$, а в полностью аморфном материале $\chi^{\mathrm{Si}}=100 \%$ [24]. Таким образом, степень кристалличности гиперпересыщенного теллуром кремния максимальна после лазерного отжига с максимальной плотностью энергии $W=2.5 \mathrm{~J} / \mathrm{cm}^{2}$. Остаточная дефектность структуры после рекристаллизации аморфных
Таблица 1. Значения $\chi^{\mathrm{Si}}$ и $f$ образцов $\mathrm{Si}$, гиперпересыщенных Те

\begin{tabular}{c|c|c|c}
\hline Параметр/Образец & $W=1.5 \mathrm{~J} / \mathrm{cm}^{2}$ & $W=2.0 \mathrm{~J} / \mathrm{cm}^{2}$ & $W=2.5 \mathrm{~J} / \mathrm{cm}^{2}$ \\
\hline$\chi^{\mathrm{Si}}, \%$ & 23.9 & 23.1 & 21.2 \\
$f, \%$ & 91.2 & 90.4 & 73.6
\end{tabular}

слоев кремния, а также часть атомов теллура, не попадающих в узлы решетки $\mathrm{Si}$ и формирующих атомные кластеры, обусловливает повышенный выход в каналированных спектрах РОР. Эффективное функционирование кремниевого фотоприемника обеспечивается при условии структурного совершенства легированного слоя и высокой степени активации введенной примеси [16,1820]. Анализ спектров РОР в режиме каналирования свидетельствует о том, что лазерный отжиг приводит также к вхождению атомов Те в узлы решетки кремния, причем степень активации примеси очень высока и составляет (73.6-91.2\%). При этом чем меньше энергия ИЛО, тем больше примеси оказывается в позициях замещения в решетке кремния.

На рис. 3 представлены спектры КРС образцов имплантированного кремния до и после термообработок. Спектр исходной кремниевой пластины характеризуется узкой симметричной полосой с максимумом при $520 \mathrm{~cm}^{-1}$, обусловленной рассеянием на оптическом фононе. После имплантации данная полоса исчезает, что говорит о полной аморфизации имплантированного слоя кремния. После проведения ИЛО полоса вновь

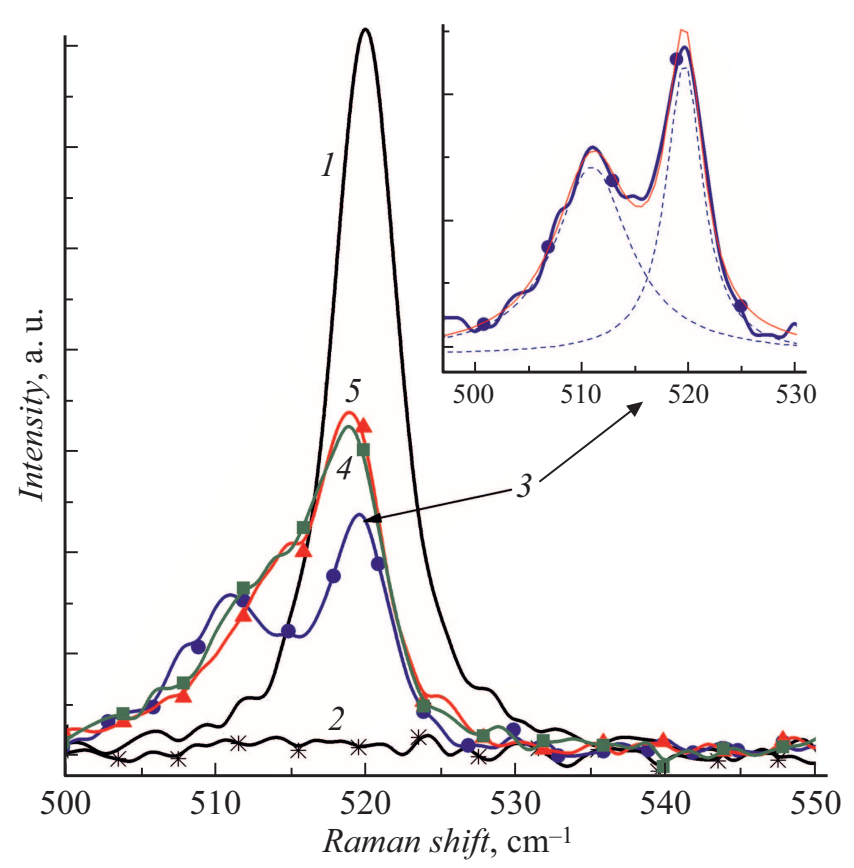

Рис. 3. Спектры комбинационного рассеяния света исходной кремниевой пластины (1) кремния, имплантированного Те, до (2) и после лазерного отжига импульсами с плотностью энергий 1.5 (3), 2 (4), 2.5 (5) J/ $\mathrm{cm}^{2}$. 
регистрируется, что свидетельствует о восстановлении кристаллической структуры легированного слоя кремния. Для образца, облученного лазерным импульсом с $W=1.5 \mathrm{~J} / \mathrm{cm}^{2}$, также регистрируется сигнал от кремниевой матрицы, причем спектр КРС в обсуждаемой спектральной области можно аппроксимировать двумя полосами: слабая полоса с максимумом при $511 \mathrm{~cm}^{-1}$ и более интенсивная при $519.7 \mathrm{~cm}^{-1}$. Проявление данных полос указывает на наличие двух рекристаллизованных слоев с разным уровнем остаточных напряжений. Это может быть обусловлено разной скоростью рекристаллизации слоев кремния с различным уровнем легирующей примеси. Повышение энергии в импульсе (до $2-2.5 \mathrm{~J} / \mathrm{cm}^{2}$ ) приводит к сдвигу низкочастотной полосы в сторону больших частот. Таким образом, с увеличением энергии в импульсе возрастает степень структурного совершенства рекристаллизованного слоя имплантированного кремния, однако полного восстановления структуры не происходит. Данные КРС соответствуют результатам РОР/К (табл. 1). Известно, что с увеличением плотности энергии наносекундного ИЛО растет толщина расплавленного слоя и время существования жидкой фазы $[25,26]$. Этим и обусловлена различная степень структурного совершенства легированного слоя в нашем случае.

\section{2. Оптические свойства}

На рис. 4 представлены спектры поглощения имплантированных образцов в диапазоне длин волн $200-2500 \mathrm{~nm}$.

Как видно, для образца сразу после имплантации $\left(\right.$ „Si $\left.+\mathrm{Te}^{\text {“ }}\right)$ наблюдается уменьшение коэффициента поглощения в видимой области и его увеличение на

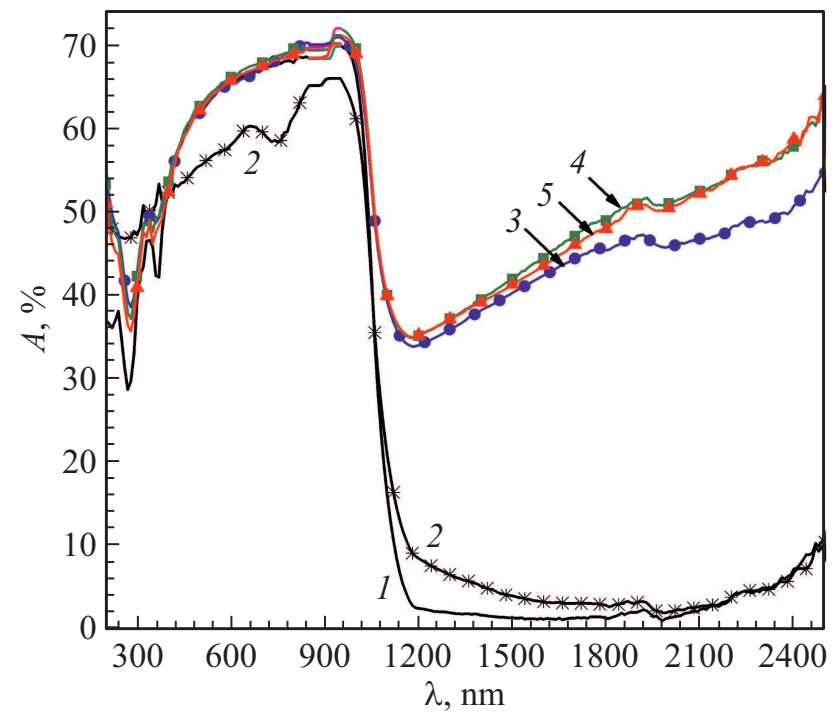

Pис. 4. Спектры поглощения исходной кремниевой пластины (1), кремния, имплантированного Те, до (2) и после лазерного отжига импульсами с плотностью энергий 1.5 (3), 2 (4), $2.5(5) \mathrm{J} / \mathrm{cm}^{2}$.
1-6\% в области 1100-2000 nm. Данный эффект, предположительно, вызван поглощением ИК фотонов на радиационных дефектах. В то же время в имплантированных образцах после ИЛО наблюдается интенсивное поглощение света с энергией меньшей, чем ширина запрещенной зоны кремния. При этом для образца после лазерного отжига с $W=1.5 \mathrm{~J} / \mathrm{cm}^{2}$ коэффициент поглощения увеличивается с $34 \%$ при $\lambda=1180 \mathrm{~nm}$ до $55 \%$ при $\lambda=2500 \mathrm{~nm}$. Эффект возрастания коэффициента поглощения с ростом длины волны для образцов после ИЛО с $W=2.0$ и $2.5 \mathrm{~J} / \mathrm{cm}^{2}$ выражен еще заметнее. В этом случае коэффициент поглощения увеличивается с $35 \%$ при $\lambda=1180 \mathrm{~nm}$ до 64 и $65 \%$ соответственно при $\lambda=2500 \mathrm{~nm}$.

Поглощение в видимом и ИК диапазонах может быть увеличено на десятки процентов при нанесении тонкого слоя $\mathrm{SiO}_{2}$ на поверхность сформированной структуры за счет подавления коэффициента отражения излучения. Коэффициент отражения света слоем $\mathrm{SiO}_{2}$ при $T=300 \mathrm{~K}$ значительно ниже, чем у кремния и составляет $0.05-0.1$, а коэффициент поглощения света $\alpha$ слоем $\mathrm{SiO}_{2} \sim 0.01 \alpha_{\mathrm{Si}}[26]$. Нарушенные и аморфизованные слои $\mathrm{Si}$ не проявляют сильного поглощения вблизи фундаментального края поглощения и коэффициент поглощения быстро уменьшается с увеличением длины волны [27]. Следовательно, высокая степень поглощения имплантированных слоев после ИЛО может быть обусловлена только высокой концентрацией атомов Те в положении замещения в решетке $\mathrm{Si}$ и формированием примесной подзоны внутри запрещенной зоны кремния $E_{g}^{\mathrm{Si}}$.

Атомы халькогенов ( $\mathrm{Te}, \mathrm{Se})$ в решетке $\mathrm{Si}$ являются двойными донорами. Введению низких концентраций атомов Те соответствует появление глубоких донорных состояний в верхней половине $E_{g}^{\mathrm{Si}}[28]: E_{C}-$ $0.199 \mathrm{eV}$ и $E_{C}-0.411 \mathrm{eV}$, отсчитываемых от дна зоны проводимости $E_{C}$. При высоких концентрациях доноров их волновые функции перекрываются, что приводит к уширению донорных уровней и формированию примесной подзоны. С дальнейшим увеличением концентрации легирующей примеси происходит увеличение ее ширины вплоть до перекрытия с зоной проводимости. В качестве грубой оценки, пороговая концентрация замещающих атомов Те в решетке $\mathrm{Si}$ для обеспечения перехода изолятор-металл, вычисленная на основе теории Мотта [29], составляет $\sim 2.65 \cdot 10^{20} \mathrm{~cm}^{-3}$ [30]. Согласно данным табл. 1 и рис. 2 , средняя концентрация замещающих атомов Те в слое $\mathrm{Si}$ толщиной $0.20 \mu \mathrm{m}$ для образцов, подвергнутых ИЛО, составляет $3.6 \cdot 10^{20}$, $3.1 \cdot 10^{20}$ и $2.2 \cdot 10^{20} \mathrm{~cm}^{-3}$ для ИЛО с $W=1.5 ; 2.0$ и $2.5 \mathrm{~J} / \mathrm{cm}^{2}$ соответственно. Ширина примесной подзоны $\Delta E_{I B}$ в соответствии с [31] определяется как

$$
\Delta E_{I B}=\frac{e^{2} N_{d}^{1 / 3}}{4 \pi \varepsilon_{0} \varepsilon_{r}},
$$

где $e-$ заряд электрона, $\varepsilon-$ диэлектрическая проницаемость вакуума, $\varepsilon_{r}-$ высокочастотная диэлектрическая проницаемость $\mathrm{Si}, N_{d}$ - концентрация доноров. 
В соответствии с (1) и приведенными выше данными для $N_{d}$ в трех режимах ИЛО получаем, что $\Delta E_{I B}$ изменяется от $0.11 \mathrm{eV}$ для $W=1.5 \mathrm{Jcm}^{2}$ до $0.07 \mathrm{eV}$ для $W=2.5 \mathrm{Jcm}^{2}$. В рамках более строгих расчетов на основе теории функционала плотности [32] для кремния с близким уровнем легирования теллуром: 1 атом теллура на 215 атомов кремния, что соответствует $2.33 \cdot 10^{20}$ at. $/ \mathrm{cm}^{3}$, ширина примесной подзоны составляет $0.25 \mathrm{eV}$. Эта зона располагается на расстоянии $0.47 \mathrm{eV}$ от валентной зоны $\Delta E(V B-I B)$ и на расстоянии $0.38 \mathrm{eV}$ от зоны проводимости кремния $\triangle E(I B-C B)$.

\section{3. Фотоэлектрические характеристики}

Гиперпересыщенные теллуром слои кремния были использованы для изготовления фотодиодов. Структурная схема приборов представлена на рис. 5. Верхние кольцеобразные никелевые электроды создавались методом магнетронного распыления мишени. Для формирования мезоструктур этот процесс сопровождался операциями фотолитографии и плазмохимического травления кремния в SF6 на глубину $2 \mu \mathrm{m}$. В качестве нижних электродов наносились слои $\mathrm{Al}$ толщиной около $200 \mathrm{~nm}$.

2.3.1. ВАX фотодиодов При измерении прямой BAX к никелевому контакту подключался отрицательный электрод, а к подложке структуры - положительный. При измерении обратной ВАХ - наоборот. На рис. $6, a, b$ приведены темновые и с подсветкой ВАХ образца после имплантации ионов $\mathrm{Te}^{+}$без термообработки при $T_{r e g}=290$ и $80 \mathrm{~K}$. Значение прямого смещения на структуре увеличивалось до $U_{\text {forw }}=3 \mathrm{~V}$. При этом максимальное значение тока составило $1.5 \mathrm{~mA}$ при $290 \mathrm{~K}$ (рис. 6, $a$ ) и $0.02 \mathrm{~mA}$ при $80 \mathrm{~K}$ (рис. 6, $b$ ). Обратные ВАХ измерялись до $U=-10 \mathrm{~V}$. При $T_{r e g}=290 \mathrm{~K}$ подсветка на прямую и обратную ветвь практически не влияет. При этом максимальное значение обратного тока составило $9 \cdot 10^{-5}$ А. Эти данные свидетельствуют о том, что механизм термоактивируемой инжекции носителей при этой температуре является доминирующим. Измерение при $T_{r e g}=80 \mathrm{~K}$ выявило сильное подавление этого механизма инжекции (рис. $6, b)$. При температуре измерения $80 \mathrm{~K}$ значение темнового обратного тока уменьшается на шесть порядков. В диапазоне напряжений смещения

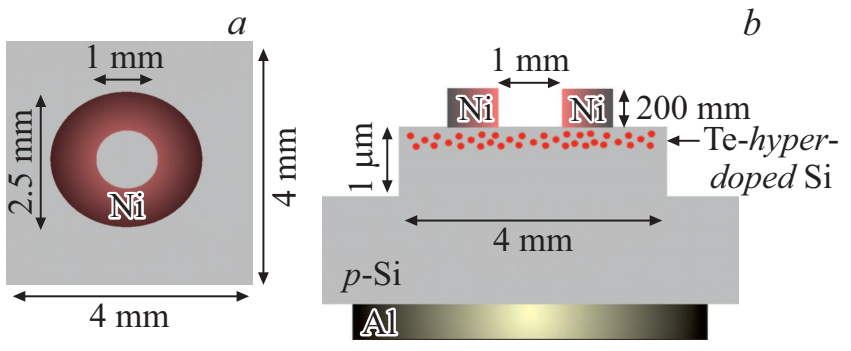

Рис. 5. Схема фотодиодной тестовой структуры: $a-$ вид свер$\mathrm{xy}, b-$ тестовая структура фотодиода с гипердопированным теллуром слоем кремния.
$U_{\text {rev }}$ от -4 до $-10 \mathrm{~V}$ подсветка увеличивает обратные токи примерно в 300 раз. Кроме того, подсветка образца приводит к увеличению прямого тока в начальной области ВАХ.

Учитывая, что после имплантации ионов $\mathrm{Te}^{+}$формируется аморфный слой кремния $(\sim 0.2 \mu \mathrm{m})$, для стабилизации структурного состояния этого слоя была проведена термообработка при $400^{\circ} \mathrm{C}$ в течение $15 \mathrm{~min}$ в атмосфере аргона. Измерения ВАХ сформированной структуры выполнялись при $290 \mathrm{~K}$ с подсветкой галогенной лампой $(T \sim 3000 \mathrm{~K})$ во всем диапазоне свечения (Full Range), а при подсветке через кремниевую пластину (IR Range) определялась фоточувствительность структуры в ИК диапазоне (рис. 7). При изменениях в режиме Full Range выбиралось расстояние от источника до приборной структуры, обеспечивающее отсутствие ее разогрева. Из рис. 7 видно, что термообработка при $400^{\circ} \mathrm{C}$ приводит к появлению фоточувствительности образца при температуре измерения $290 \mathrm{~K}$. При этом максимальное значение отношения тока при засветке $\left(I_{L}\right)$ к темновому току $\left(I_{D}\right)$ составляет $I_{L} / I_{D}=17$ и достигается при отрицательном смещении $U_{\mathrm{rev}}=-2 \mathrm{~V}$. Подсветка образца в ИК диапазоне увеличивает обратный ток в 4 раза при напряжении смещения $U_{\text {rev }}$ от -1.5 до $-2 \mathrm{~V}$.

ИЛО образцов при различных энергиях лазерного воздействия приводит к появлению фототока при нулевом смещении и засветке галогенной лампой во всем диапазоне. При этом величина фото-ЭДС полученных структур составляет $0.1-0.2 \mathrm{~V}$. ВАХ структуры после ИЛО с энергией $2 \mathrm{~J} / \mathrm{cm}^{2}$, измеренные при 290 и $80 \mathrm{~K}$, изображены на рис. $6, c, d$. Засветка образца при комнатной температуре незначительно увеличивает ток обратной ветви ВАХ и практически не влияет на изменение тока прямой ветви ВАХ при напряжении $U_{\text {forw }}$ более $0.2 \mathrm{~V}$. Соотношение $I_{L} / I_{D}$, стремительно увеличивается с ростом напряжения обратного смещения от -10 до $0 \mathrm{~V}$. Темновой ток фотодиодной структуры, измеренный при $80 \mathrm{~K}$, на 4 порядка меныше темнового тока, измеренного при комнатной температуре (рис. $6, d$ ). Засветка образца галогенной лампой при низкой температуре приводит к увеличению тока обратной ветви на 2-3 порядка в диапазоне напряжений $U_{\mathrm{rev}}$ от -0.5 до $-10 \mathrm{~V}$. BAX структур после ИЛО с различными энергиями имеют схожий вид. В табл. 2 представлены значения прямого тока, измеренного при напряжении $U_{\text {forw }}=4 \mathrm{~V}$, темнового тока и соотношения $I_{L} / I_{D}$ для фотодиодных структур при температурах 290 и $80 \mathrm{~K}$. Значения $I_{L} / I_{D}$ получены при напряжении смещения $-10 \mathrm{~V}$ и засветке галогенной лампой во всем диапазоне. Из табл. 2 видно, что темновой ток структуры, изготовленной после ИЛО с энергией $2.5 \mathrm{~J} / \mathrm{cm}^{2}$, значительно превышает темновые токи образцов, отожженных лазерным импульсом с энергиями 1.5 и $2 \mathrm{~J} / \mathrm{cm}^{2}$. Отношение фототока к темновому току, полученное при комнатной температуре, слабо зависит от энергии облучения и находится в пределах 1.3-1.5. С другой стороны, эффективность фотопреобразования, 

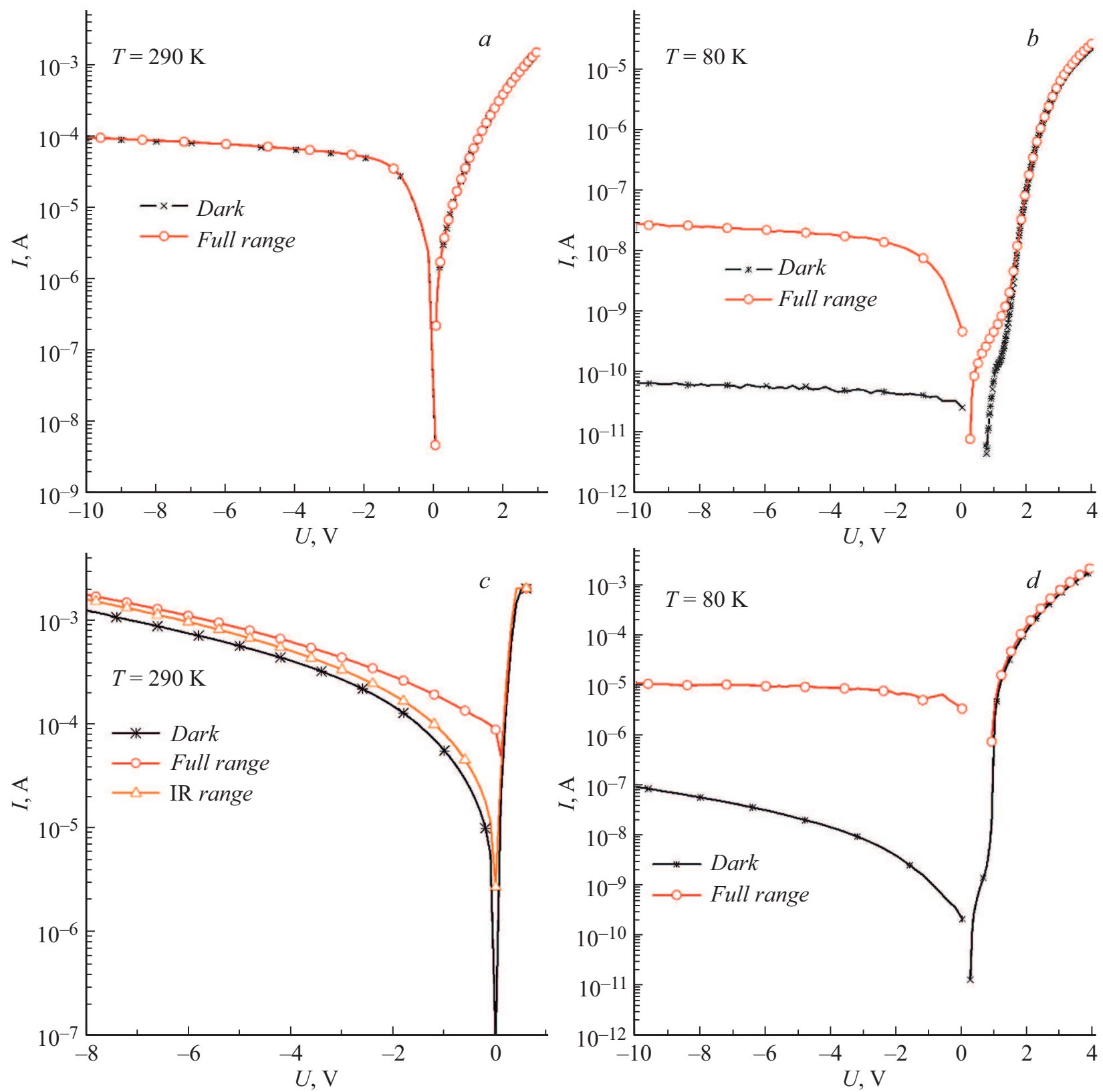

Рис. 6. Прямые и обратные ВАХ кремния, имплантированного Те, до $(a, b)$ и после лазерного отжига $(c, d)$ импульсом с $W=2 \mathrm{~J} / \mathrm{cm}^{2}$, измеренные без подсветки и с подсветкой при $T_{r e g}=290 \mathrm{~K}(a, c)$ и $80 \mathrm{~K}(b, d)$.

измеренная при температуре $80 \mathrm{~K}$, существенно зависит от энергии облучения и стремительно уменьшается с 1200 до 95 при увеличении энергии импульса лазерного воздействия от 1.5 до $2.5 \mathrm{~J} / \mathrm{cm}^{2}$. Эту зависимость можно объяснить наличием дефектов с различной энергией активации, концентрация которых зависит от энергии лазерного отжига. Наибольшей эффективностью фотопреобразования, измеренной при температурах 290 и $80 \mathrm{~K}$ и напряжении смещения $-10 \mathrm{~V}$, обладает образец, отожженный при $W=1.5 \mathrm{~J} / \mathrm{cm}^{2}$.

Особого внимания заслуживают эффекты, обусловленные дополнительным термоотжигом при $400^{\circ} \mathrm{C}$ в течение $15 \mathrm{~min}$. Так как шаг измерения $\mathrm{BAX}$ составлял
$0.2 \mathrm{~V}$, максимальная эффективность фотопреобразования (параметр $I_{L} / I_{D}$ ) вычислялась при напряжении смещения $U_{\text {rev }}=-0.2 \mathrm{~V}$. В табл. 3 представлены максимальные значения $I_{L} / I_{D}$, измеренные до и после термообработки образцов при $400^{\circ} \mathrm{C}$. Наибольшей эффективностью фотопреобразования в ИК диапазоне до и после термообработки, а также в видимом диапазоне до термообработки обладает образец, прошедший ИЛО с $W=2 \mathrm{~J} / \mathrm{cm}^{2}$. Результаты приведенных выше структурных и оптических свойств сформированных слоев свидетельствуют о том, что этой плотности энергии ИЛО соответствует как хорошее структурное совершенство слоя, так и высокий процент замещающей фракции теллура в решетке крем- 
ния. Термообработка привела к увеличению значения $I_{L} / I_{D}$ при засветке галогенной лампой во всем диапазоне. С другой стороны, термообработка практически не повлияла на интенсивность фотопреобразования при засветке в ИК диапазоне.

В целом такие термообработки после ИЛО могут вызывать улучшение качества кристалличности легированного слоя, увеличение уровня электрической активации внедренной примеси и поглощения в ИК диапазоне за счет развала и активации теллуровых комплексов, сформированных в процессе ИЛО. Несомненно, требуются дополнительные исследования с целью повышения эффективности фотодетекторов в видимой и ИК областях. Это может быть достигнуто посредством специального дизайна верхнего и нижнего электродов для усиления эффективности сбора генерируемых светом носителей, а также применением антиотражающего покрытия. Кроме того, пассивация верхней стороны или обеих частей структуры (тонким слоем $\mathrm{SiO}_{2}$ или $\mathrm{Si}_{3} \mathrm{~N}_{4}$ ), а также использование точечного контакта на обратной стороне детектора будут значительно подавлять поверхностную рекомбинацию носителей. Характеристики диодов и их фоточувствительность сильно зависят и от условий изготовления, включая тип и уровень легирования подложки и имплантированного слоя, параметры ИЛО и режимы финальной равновесной термообработки. С целью максимально эффективного использования генерируемых светом носителей при комнатной температуре промежуточная подзона, создаваемая гипердопированием халькогенами, должна быть изолирована достаточной щелью как от зоны проводимости, так и валентной зоны. Для

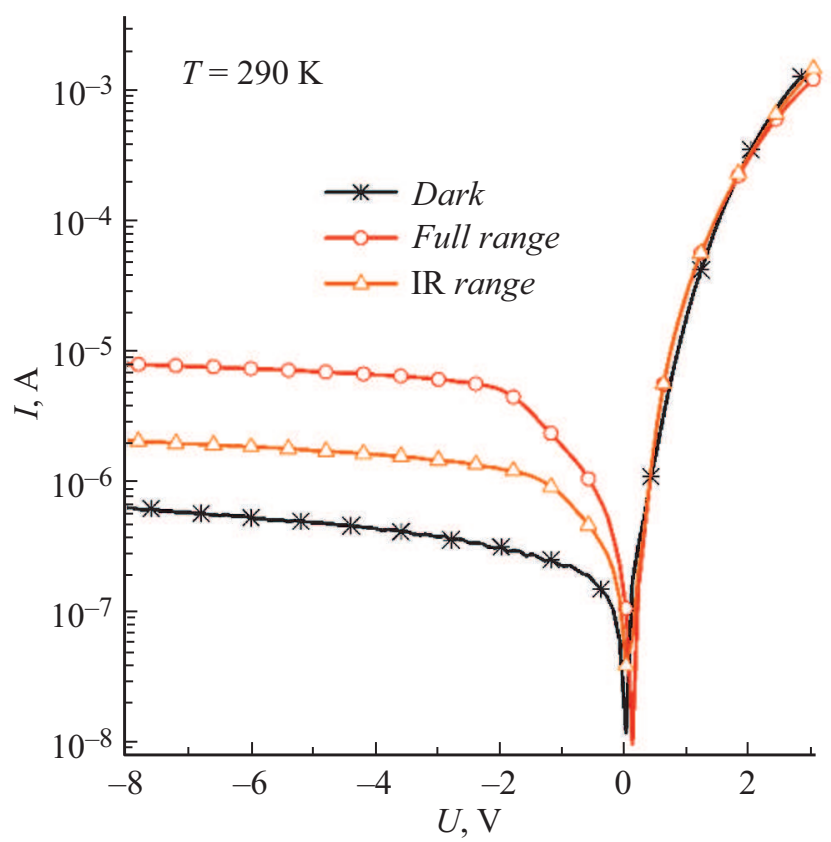

Рис. 7. ВАХ кремния, имплантированного Те, после термообработки при $400^{\circ} \mathrm{C}$, измеренные без подсветки и с подсветкой при $T_{\text {reg }}=290 \mathrm{~K}$. эффективного сбора носителей тока представляет интерес и разработка горизонтальной (планарной) структуры таких фотоприемников.

2.3.2. Вольт-фарадные характеристики Из емкостных измерений при различных напряжениях и температурах 290 и $80 \mathrm{~K}$ определялась концентрация носителей заряда $N(x)$ в менее легированной области исследуемых структур и ширина области пространственного заряда (ОПЗ). На рис. 8, $a$ приведены $C-U$-характеристики структуры без ИЛО, измеренные при 290 и $80 \mathrm{~K}$. Значения емкости при нулевом смещении составляет 30-33 pF и слабо зависит от температуры. При обеих температурах зависимость $C(U)$ имеет немонотонный вид, который в наибольшей степени проявляется при $T=290 \mathrm{~K}$. Столь необычный вид $C-U$-характтеристики получен в работе [33] для кремниевого диода, содержащего в симметричном $p-n$-переходе $\delta$-слой точечных трехзарядных дефектов.

На рис. 8, $b$ представлено распределение концентрации носителей заряда $N(x)$ в менее легированной области этой структуры. Зависимости $N(x)$ определялись в предположении резко асимметричного $p-n$-перехода из $C-U$-характеристик, приведенных на рис. $8, a$. Обращает на себя внимание большая ширина области пространственного заряда $(\approx 6.5 \mu \mathrm{m})$ при нулевом смещении на образце и несколько необычный „спадающий“ вид зависимостей $N(x)$. Ширина ОПЗ увеличивается с ростом величины $E_{g}$ (см. ниже, выражение (2)). Случаю аморфного кремния соответствует ширина запрещенной зоны $E_{g} \approx 1.7-1.8 \mathrm{eV}$. С уменьшением температуры ширина ОПЗ увеличивается в два раза, что может свидетельствовать о высокой концентрации радиационных дефектов в данной области структуры после имплантации ионов $\mathrm{Te}^{+}$, а также об уменьшении концентрации подвижных носителей $N(T)$ при низких $T$ (см. (2)). Следует отметить, что для систем с большой шириной ОПЗ характерна более высокая вероятность регистрации низкоэнергетических квантов за счет повышения вероятности поглощения таких квантов, генерации и разделения носителей тока разного знака в этой области [34]. Только кванты, поглощенные в ОПЗ, дают вклад в фотогенерационный ток.

$C-U$-характеристики образцов после ИЛО, измеренные при 290 и $80 \mathrm{~K}$, приведены на рис. 9, а. Здесь немонотонная зависимость емкости от обратного смещения наблюдается только при 290 К. В результате ИЛО значение емкости образцов при нулевом смещении возросло на порядок величины и более при $T=290 \mathrm{~K}$ и почти в 10 раз при $T=80 \mathrm{~K}$. С понижением температуры образца значение барьерной емкости уменьшается на $50 \mathrm{pF}$ (при нулевом смещении) для структуры после ИЛО при $W=2 \mathrm{~J} / \mathrm{cm}^{2}$ и примерно на 100 и $200 \mathrm{pF}$ для режима ИЛО с $W=1.5$ и $2.5 \mathrm{~J} / \mathrm{cm}^{2}$ соответственно. Самое высокое значение барьерной емкости регистрируется для структуры после ИЛО при $W=2.5 \mathrm{~J} / \mathrm{cm}^{2}$. 
Таблица 2. Величины темновых токов и относительные эффективности фотопреобразования фотодетекторов, сформированных в различных режимах термообработки

\begin{tabular}{|c|c|c|c|c|}
\hline$T_{r e g}, \mathrm{~K}$ & $\begin{array}{c}\text { Плотность энергии } \\
\text { лазерного импульса, } \mathrm{J} / \mathrm{cm}^{2}\end{array}$ & $I_{\text {forw }}^{\max }, \mathrm{mA}$ & $\begin{array}{l}I_{\text {rev }} \text { темновой при } \\
U_{\text {rev }}=-10 \mathrm{~V}, \mathrm{~mA}\end{array}$ & $\begin{array}{c}I_{L} / I_{D} \text { при } \\
U_{\text {rev }}=-10 \mathrm{~V}, \text { a.u. }\end{array}$ \\
\hline \multirow{4}{*}{290} & 0 & 1.5 & $9 \cdot 10^{-2}$ & $\sim 1$ \\
\hline & 1.5 & 63.5 & 1.2 & $\sim 1.5$ \\
\hline & 2 & 75 & 1.6 & $\sim 1.3$ \\
\hline & 2.5 & 100 & 1.2 & $\sim 1.4$ \\
\hline \multirow{4}{*}{80} & 0 & 2 & $8 \cdot 10^{-8}$ & 300 \\
\hline & 1.5 & 2 & $3 \cdot 10^{-5}$ & 1200 \\
\hline & 2 & 2.1 & $9 \cdot 10^{-5}$ & 1000 \\
\hline & 2.5 & 1.7 & $10^{-3}$ & 95 \\
\hline
\end{tabular}

Таблица 3. Фотоэлектрическая эффективность структур при $U_{\text {rev }}=-0.2 \mathrm{~V}$ и $T=290 \mathrm{~K}$, измеренная до и после термообработки $\left(400^{\circ} \mathrm{C}, 10 \mathrm{~min}\right)$

\begin{tabular}{|c|c|c|c|}
\hline $\begin{array}{l}\text { Диапазон } \\
\text { подсветки }\end{array}$ & $\begin{array}{c}\text { Плотность } \\
\text { энергии ИЛО, J/cm² }\end{array}$ & $\begin{array}{c}I_{L} / I_{D}, \text { a. u. до } \\
\text { термообработки }\end{array}$ & $\begin{array}{r}I_{L} / I_{D}, \text { a. u. после } \\
\text { термообработки }\end{array}$ \\
\hline \multirow{3}{*}{$\begin{array}{c}\text { Полный } \\
\text { диапазон }\end{array}$} & 1.5 & 2.7 & 8.3 \\
\hline & 2 & 6.8 & 10.2 \\
\hline & 2.5 & 4.3 & 10.9 \\
\hline \multirow{3}{*}{ ИК } & 1.5 & 1.3 & 1.5 \\
\hline & 2 & 1.9 & 1.8 \\
\hline & 2.5 & 1.3 & 1.4 \\
\hline
\end{tabular}

Для структуры, сформированной после ИЛО с $W=2 \mathrm{~J} / \mathrm{cm}^{2}$ (рис. 9, $b$ ) по сравнению с образцом без ИЛО, наблюдается существенное уменьшение ширины ОП3 ( 1.4 $\mu \mathrm{m}$ при $T=290 \mathrm{~K}$ и нулевом смещении), а также увеличение концентрации дырок. При $T_{r e g}=80 \mathrm{~K}$ концентрация дырок составляет $\sim 1.5 \cdot 10^{16} \mathrm{~cm}^{-3}$. При комнатной температуре значение $N$ изменяется от $3 \cdot 10^{16} \mathrm{~cm}^{-3}$ (при нулевом смещении) до $6 \cdot 10^{15} \mathrm{~cm}^{-3}$, что примерно на порядок величины превышает данные из ирвиновской кривой для кремния $p$-типа с $\rho=10 \Omega \cdot \mathrm{cm}$. Следует отметить более высокое значение концентрации подвижных носителей при азотных температурах по сравнению со случаем для $T_{r e g}=290 \mathrm{~K}$.

После ИЛО с $W=1.5 \mathrm{~J} / \mathrm{cm}^{2}$ структура характеризуется более низкой концентрацией подвижных дырок при обеих температурах измерения, чем для образца после ИЛО при $W=2 \mathrm{~J} / \mathrm{cm}^{2}$. Ширина ОПЗ при нулевом смещении также меньше, чем у предыдущего образца при $T_{r e g}=290 \mathrm{~K}$ и больше при $T_{r e g}=80 \mathrm{~K}$. В определенной мере эти результаты согласуются с тем, что обсуждаемый образец прошел менее интенсивный ИЛО, чем предыдущий. Это относится к концентрации подвижных дырок и ширине ОПЗ при низких температурах.
Для структуры, подвергнутой ИЛО с $W=2.5 \mathrm{~J} / \mathrm{cm}^{2}$, зависимость $N(x)$ имеет немонотонный вид (рис. 9). Концентрация подвижных дырок при $T_{r e g}=290 \mathrm{~K}$ больше, чем у двух предыдущих образцов, а при $T_{\text {reg }}=80 \mathrm{~K}$ такая же, как и у образца после ИЛО с $W=2 \mathrm{~J} / \mathrm{cm}^{2}$. Ширина ОПЗ при нулевом смещении также, по сравнению с двумя предыдущими системами, меньше. При приложении к диоду обратного напряжения свободные носители заряда вытесняются из областей, прилегающих к $p$-n-переходу: область объемного заряда становится шире. Характеристики сформированных $p-n$-переходов, такие, как концентрация носителей тока, высота барьера, определяют ширину ОПЗ.

Ширина ОПЗ $V$, измеренная для структур после ИЛО, достаточно хорошо описывается выражением [34] для плоского конденсатора

$$
V=\frac{\varepsilon \varepsilon_{0} \cdot S}{C}\left[\frac{2 \varepsilon \varepsilon_{0}\left(U_{p n}+U\right)}{e N}\right]^{1 / 2},
$$

где $\varepsilon=12.5-$ диэлектрическая постоянная кремния, $\varepsilon_{0}-$ диэлектрическая постоянная вакуума, $\varepsilon_{0}=8.85 \cdot 10^{-12} \mathrm{~F} / \mathrm{m}, S$ - площадь верхнего электрода тестовой структуры (в нашем случае $S=4.121 \mathrm{~mm}^{2}$ ), 


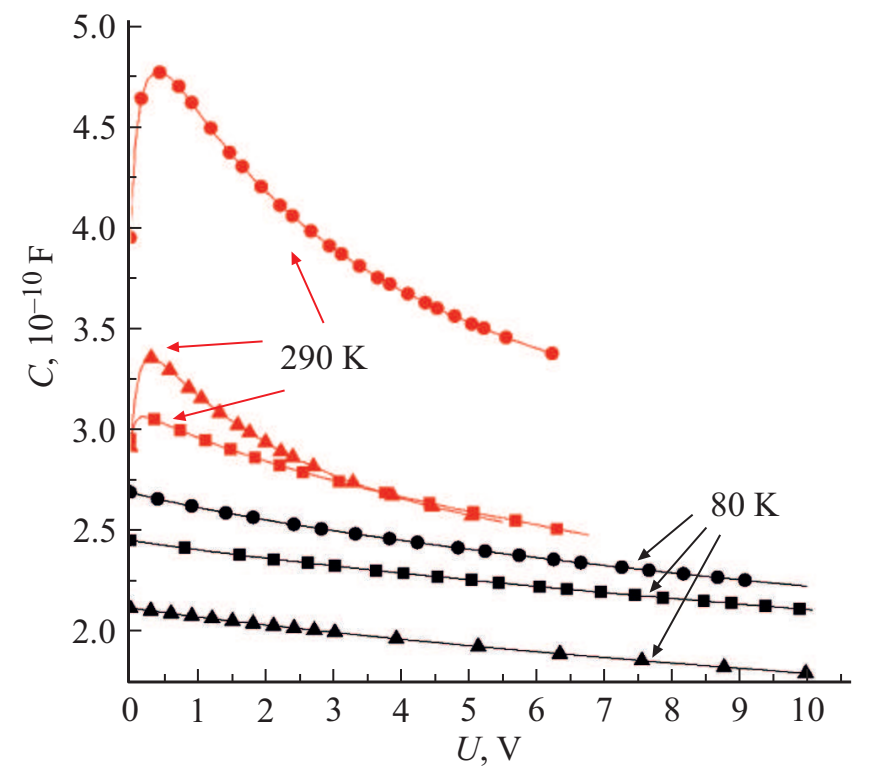

Рис. 8. $C-U$-характеристики кремния, имплантированного $\mathrm{Te}$, после лазерного отжига импульсом с $W=1.5 \mathrm{~J} / \mathrm{cm}^{2}(\boldsymbol{\Lambda})$, $W=2 \mathrm{~J} / \mathrm{cm}^{2}\left(\right.$ 口) и $W=2.5 \mathrm{~J} / \mathrm{cm}^{2}(\bullet)$, измеренные при $T_{\text {reg }}=290$ и $80 \mathrm{~K}$.

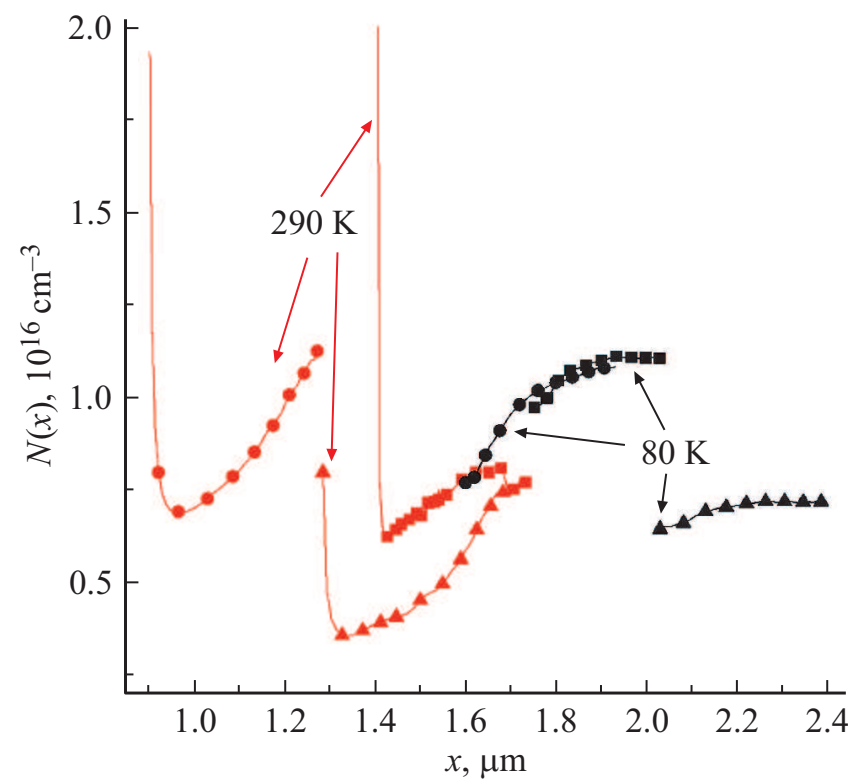

Рис. 9. Распределения концентрации носителей заряда $N(x)$, рассчитанные из $C-U$-характеристик кремния, имплантированного Те, после лазерного отжига импульсом с $W=1.5 \mathrm{~J} / \mathrm{cm}^{2}(\boldsymbol{\Delta}), W=2 \mathrm{~J} / \mathrm{cm}^{2}(\square)$ и $W=2.5 \mathrm{~J} / \mathrm{cm}^{2}(\bullet)$, измеренных при $T_{\text {reg }}=290$ и $80 \mathrm{~K}$.

$U_{p n}$ по величине равно примерно ширине запрещенной зоны кремния, выраженной в вольтах $(1.12 \mathrm{~V}), U$ напряжение обратного смещения, $N-$ концентрация подвижных носителей в менее легированной области. Для рассматриваемых систем после ИЛО $V=\frac{456 \mu \mathrm{m} \cdot \mathrm{p} F}{C(\mathrm{pF})}$.

\subsection{DLTS-спектроскопия образцов}

Определение энергии активации эмиссии и сечений захвата носителей заряда осуществлялось методом нестационарной емкостной спектроскопии глубоких уровней (DLTS) [35]. Длительность импульса заполнения ловушек составляла $10^{-2} \mathrm{~s}$, а величина напряжения смещения $U_{\text {biad }}$ от -3 до $-16 \mathrm{~V}$. Спектры измерялись в диапазоне температур $80-300 \mathrm{~K}$ в режиме заполнения ловушек основными носителями заряда. Напряжение заполнения $U_{\text {occ }}=0 \mathrm{~V}$, окно скоростей эмиссии $e=19 \mathrm{~s}^{-1}$.

На рис. 10 показаны спектры DLTS для всех четыpex обсуждаемых систем. Для ловушек H1-H3 были определены параметры, энергия активации и сечение захвата. Ловушке Н1 соответствует глубокий уровень в запрещенной зоне $\mathrm{Si} E_{V}+0.25 \mathrm{eV}$ и сечение захвата $\sigma=2.5 \cdot 10^{-12} \mathrm{~cm}^{-2} ; \mathrm{H} 2-E_{V}+0.24 \mathrm{eV}$ и сечение захвата $\sigma=6.7 \cdot 10^{-15} \mathrm{~cm}^{-2}$ и $\mathrm{H} 3-E_{V}+0.34 \mathrm{eV}$ и сечение захвата $\sigma=1.8 \cdot 10^{-15} \mathrm{~cm}^{-2}$. Обращает на себя внимание очень большое сечение захвата носителей у ловушки Н1. Такие значения соответствуют мелким легирующим примесям.

Наиболее интенсивный пик Н3 в DLTS-спектре, вероятнее всего, связан с наличием примесной подзоны в запрещенной зоне кремния. Для рассмотренного выше уровня легирования кремния теллуром $\left(2.2-3.6 \cdot 10^{20} \mathrm{~cm}^{-3}\right)$ эта подзона может располагаться на расстоянии $\sim 0.3-0.5 \mathrm{eV}$ от валентной зоны. Выяснение природы других регистрируемых пиков в спектре требует дополнительных исследований за рамками настоящей работы.

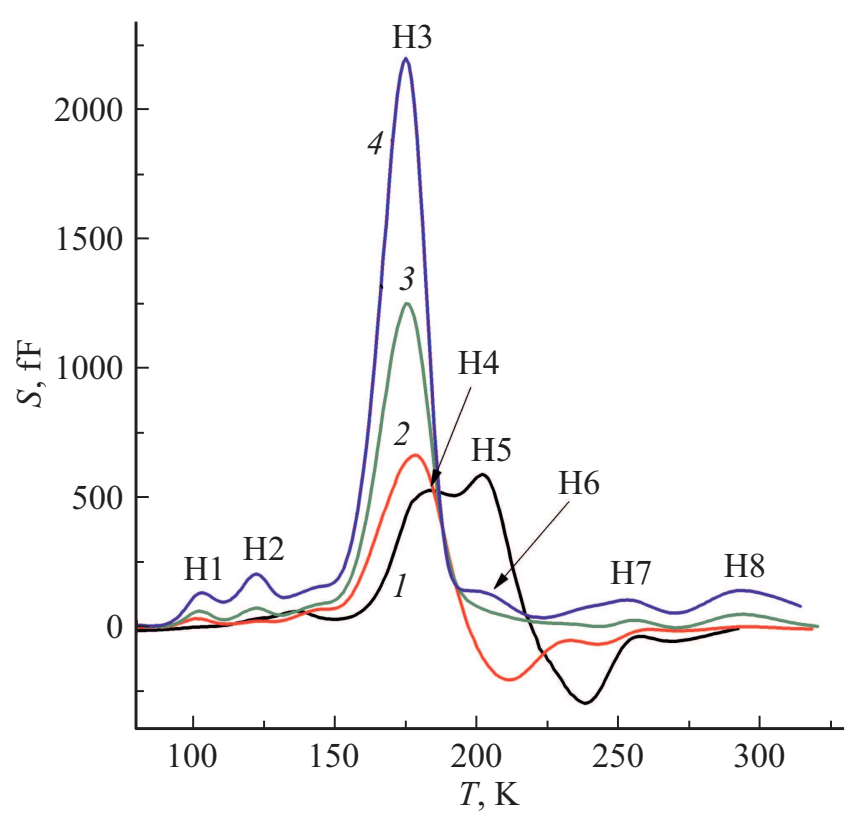

Рис. 10. Спектры DLTS кремния, имплантированного Те, до и после лазерного отжига, измеренные в режиме заполнения ловушек основными носителями заряда: 1 - без отжига; $2-W=1.5 \mathrm{~J} / \mathrm{cm}^{2} ; 3 W=2 \mathrm{~J} / \mathrm{cm}^{2} ; 4-W=2.5 \mathrm{~J} / \mathrm{cm}^{2}$. 


\section{Заключение}

Имплантацией ионов Te с энергией $200 \mathrm{keV}$ дозой $1 \cdot 10^{16} \mathrm{~cm}^{-2}$ с последующим наносекундным лазерным отжигом при плотности энергии в импульce $1.5-2.5 \mathrm{Jcm}^{2}$ получены слои кремния, гипердопированные теллуром до концентрации $(3-5) \cdot 10^{20} \mathrm{~cm}^{-3}$. По данным РОР внедренная примесь практически равномерно распределена в имплантированном слое на глубине от поверхности до $190 \mathrm{~nm}$. При этом 70-90\% внедренной примеси находится в позиции замещения в решетке кремния.

В кремнии, гиперпересыщенном теллуром, наблюдается эффективное поглощение фотонов с энергией меньше ширины запрещенной зоны кремния, т.е. в области длин волн $\lambda>1100 \mathrm{~nm}$, вплоть до предельно измеренной $\lambda=2500 \mathrm{~nm}$. Этот процесс обусловлен формированием примесной подзоны в запрещенной зоне кремния. При этом коэффициент поглощения увеличивается с $34-35 \%$ при $\lambda=1180 \mathrm{~nm}$ до 55-65\% при $\lambda=2500 \mathrm{~nm}$. Это вызвано хорошей рекристаллизацией имплантированного слоя кремния вследствие лазерного отжига и внедрения 70-90\% примеси в позицию замещения в кристаллической решетке кремния.

На тестовых структурах фотоприемников определено влияние режимов ИЛО и последующего низкотемпературного отжига $\left(400^{\circ} \mathrm{C}, 15 \mathrm{~min}\right)$ на фоточувствительность их как в видимом, так и в ближнем ИК диапазонах. Впервые обнаружена фоточувствительность легированных теллуром аморфных слоев $\mathrm{Si}$ в ИК области после указанного низкотемпературного отжига.

Приведен ряд рекомендаций по оптимизации дизайна приборной структуры и технологических условий их изготовления с целью значительного увеличения эффективности сбора генерируемых светом носителей тока. В таком случае созданные структуры будут представлять интерес как в качестве фотоприемных в ИК диапазоне длин волн, так и при изготовлении эффективных солнечных элементов на кремнии и по кремниевой технологии.

\section{Конфликт интересов}

Авторы заявляют, что у них нет конфликта интересов.

\section{Список литературы}

[1] R. Soref. Nat. Photonics, 9, 358 (2015). DOI: $10.1038 /$ nphoton. 2015.87

[2] X. Liu, B. Kuyken, G. Roelkens, R. Baets, R.M. Osgood Jr, W.M.J. Green. Nat. Photonics, 6, 667 (2012). DOI: $10.1038 /$ nphoton.2012.221

[3] J.J. Ackert, D.J. Thompson, L. Shen, A.C. Peacock, P.E. Jessop, G.T. Reed, G.Z. Mashanovich, A.P. Knights. Nat. Photonics, 9, 393 (2015). DOI: 10.1038/nphoton.2015.81

[4] P. Chaisakul, D. Marris-Morini, G. Isella, D. Chrastina, X. Le Roux, S. Edmond, E. Cassan, J.-R. Coudevylle, L. Vivien. Appl. Phys. Lett., 98, 131112 (2011). DOI: $10.1063 / 1.3574539$
[5] M. Casalino, G. Coppola, M. Iodice, I. Rendina, L. Sirleto. Sensors, 10, 10571 (2010). DOI: 10.3390/s101210571

[6] J. Bradley, P. Jessop, A. Knights. Appl. Phys. Lett., 86, 241103 (2005). DOI: 10.1063/1.1947379

[7] J. Doylend, P. Jessop, A. Knights. Opt. Express, 18, 14671 (2010). DOI: 10.1364/OE.18.014671

[8] A. Rogalski. Prog. Quantum. Electron, 27, 59 (2003). DOI: 10.1016/S0079-6727(02)00024-1

[9] N. Sclar. Prog. Quantum. Electron, 9, 149 (1984). DOI: $10.1016 / 0079-6727(84) 90001-6$

[10] C.B. Simmons, A.J. Akey. J.P. Mailoa, D. Recht, M.J. Aziz, T. Bounassisi. Adv. Fun Mater., 24, 2852 (2014). DOI: $10.1002 / \mathrm{adfm} .201303820$

[11] X. Qiu, Z. Wang, X. Hou, X. Yu, D. Yang. Photonics Res., 7, 351 (2019). DOI: 10.1364/PRJ.7.000351

[12] E. Garcia-Hemme, R. Garcia-Hernansanz, J. Olea, D. Pastor. A. del Prado, I. Mártil, G. Gonzáles-Diaz. Appl. Phys. Lett., 103, 032101 (2013). DOI: 10.1063/1.4813823

[13] H. Vydyanath, J. Lorenzo, F. Kröger. J. Appl. Phys., 49, 5928 (1978). DOI: 10.1063/1.324560

[14] M.T. Winkler, D. Recht, M.J. Sher, A.J. Said, E. Mazur, M.J. Aziz. Phys. Rev. Lett., 106, 178701 (2011). DOI: 10.1103/PhysRevLett.106.178701

[15] H. Mehrer. Diffusion in Solids: Fundamentals, Methdos, Material, Diffusion-Controlled Processes (Springer Science and Business Media, NY., 2007), v. 155.

[16] I. Umezu, J.M. Warrender, S. Charnvanichborikarn, A. Kohno, J.S. Williams, M. Tabbal, D.G. Papazoglou, Xi-Ch. Zhang, M.J. Aziz. J. Appl. Phys., 113, 213501 (2013). DOI: $10.1063 / 1.4804935$

[17] E. Schibli, A.G. Milnes. Mater. Sci. Engineer., 2, 173 (1967). DOI: $10.1016 / 0025-5416(67) 90056-0$

[18] F.F. Komarov, G. Ivlev, G. Zayats, A. Komarov, N. Nechaev, I. Parkhomenko, L. Vlasukova, E. Wendler, S. Miskiewicz. Acta Phys. Polonica, A136, 254 (2019). DOI: $10.12693 /$ APhysPolA.136.254

[19] F.F. Komarov, N. Nechaev, G. Ivlev, L. Vlasukova, I. Parkhomenk̄o, E. Wendler, I.A. Romanov, Y. Berencén, V.V. Pilko, D.V. Zhigulin, A.F. Komarov. Vacuum, 178, 109434 (2020). DOI: 10.1016/j.vacuum.2020.109434

[20] Y. Berencén, S. Prucnal, F. Liu, I. Scorupa, R. Hübner. Scientific Reports, 7, 43688 (2017). DOI: 10.1038/srep43688

[21] M. Mayer, SIMNRA User's Guide (Max-Planck-Institut fur Plasmaphysik, Garching, 1997)

[22] D.V. Lang. Appl. Phys., 45, 3023 (1974). DOI: $10.1063 / 1.1663719$

[23] A.F. Komarov, F.F. Komarov, P. Żukowski, C. Karwat, A.L. Shukan. Nukleonika, 44, 363 (1999).

[24] L.C. Feldman, W. Mayer, S.T. Picraux. Materials Analysis by Ion Channeling: Submicron Crystallography (Elsevier, NY., 1982).

[25] Ф.Ф. Комаров, А.П. Новиков, В.С. Соловьев, С.Ю. Ширяев. Дефекты структуры в ионно-имплантированном кремнии (Университетское, Минск, 1990)

[26] В.Е. Борисенко. Твердофазные процессы в полупроводниках при импульсном нагреве (Навука і тэхніка, Минск, 1992)

[27] W. Wesch, E. Glaser, G. Götz, H. Karge, R. Proger. Phys. Stat. Sol., 65, 225 (1981), DOI: 10.1002/pssa.2210650126

[28] R. Shaub, G. Pensl, M. Schulz, C. Holm. Appl. Phys., A34, 215 (1984). DOI: 10.1007/BF00616575. 
[29] N.F. Mott. Contemp. Phys., 14, 401 (1973).

DOI: $10.1080 / 00107517308210764$

[30] M. Wang, A. Debernardi, Y. Berencén, R. Heller, C. Xu, Y. Yuan, Y. Xie, R. Böttger, L. Rebohle, W. Skorupa, M. Helm, S. Prucnal, Sh. Zhou. Phys. Rev. Appl., 11, 054039 (2019). DOI: $10.1103 /$ PhysRevApplied.11.054039

[31] E.F. Schubert. Doping III-V Semiconductors (Cambridge University Press, Cambridge, 1993)

[32] K. Sánchez, I. Aguilera, P. Palacios, P. Wahnón. Phys. Rev., B82, 165201 (2010). DOI:10.1103/Phys.RevB.82.165201

[33] Н.А. Поклонский, А.И. Ковалев. Приборы и методы измерений, 9 (2), 130 (2018).

[34] М.Е. Левинштейн, Г.С. Симин. Барьеры от кристалла до интегральной схемы (Наука, М., 1987)

[35] D.V. Lang. J. Appl. Phys., 45 (2), 3023 (1974).

DOI: $10.1063 / 1.1663719$ 